\title{
USING GEOSEMIOTIC APPROACH, LEARNERS CREATE THEIR OWN LINGUISTIC LANDSCAPE FOR DEVELOPING MULTIMODAL COMPETENCIES: TASK-BASED
}

\author{
Siusana Kweldju \\ UniversitasNegeri Malang \\ siusana.kweldju.fs@um.ac.id
}

\begin{abstract}
In the digital age, the notion of text has broadened to include digitally constructed multimodal texts. Meaning-making in everyday life is not only based on verbal language as the only mode, but also visual images. Students need more learning assignments and activities to develop their multimodal communication skills. To meet this need, a project utilizing linguistic landscape as a learning context is created for its rich multimodal representations. Task-based approach is adopted to facilitate a triple-track solution: improving students' general English and display English proficiency, raising the students' multimodal literacy, and developing their collaborative skill. The reason to employ task-based approach is because it strengthens the learners' opportunity to do real-world-relevant projects to promote both their language acquisition and their collaborative skills. The project is completed when learners in teams give their presentations as their learning out comes.
\end{abstract}

Keywords: Geosemiotic Approach, Linguistic Landscape, Multimodal Competencies, Task-based approach

\section{INTRODUCTION}

In the advancement and increasing use of digital and communication technology of the 21st century, literacy in educational contexts should be redefined, especially when digital technology is relatively easy to learn by young people. To meet the requirement of the 21 st century, there is a need to reorient ESL instruction towards multimodal pedagogical practices, as ESL learners today are digital natives who need to be skillful in both interpreting and producing multimodal texts (Ganapsthy \& Seetharam, 2016).

Another reason that literacy today should be multimodal is the fact that the society itself is multimodal (Lirola \& Castejón, 2014).Literacy today should conceptualize the link between reading and writing activities and the social structures in which they are embedded and which they help shape (Barton \& Hamilton, 1998).Today's societies live in a new way of communication landscape; information is accessed from web or digital media sources full of images which may appear and function differently than they used to be. In the past, multimodal skills belonged to a specialized professional or illustrator only, but today with the advancement of digital technology it is learnable by everyone, especially by young people. Image has overshadowed word. It has even increasingly designed to be more prominent than the written elements.

In short, language instruction in the globalized society should go beyond reading and writing only. Literacy has traditionally been associated with the ability to read and write typographical text only (e.g. Gee, 1996; Cope \& Kalantzis, 2000). However, today in its real context, messages in authentic communication are also delivered through the integrated composition of both written and visual texts. Variety of texts associated with information and multimedia technologies are incorporated to literacy for the multimodal meaning-making representations.

As all learning activities are intended to develop students' knowledge, skills and attitude, the aim of the present multiliteracy task is to promote the students' spoken and written English language skills, multiliteracy, and collaborative skills using linguistic landscape as a pedagogical tool. In the task students construct new signage or improve the existing multimodal linguistic landscape of SukarnoHatta Boulevard in Malang City, Indonesia.

Linguistic landscape in the present study is viewed from the geosemiotic perspective; that is the study of social meaning of signs and discourses and of actions in the material world.

Students develop their spoken and written English skills when they work collaboratively with their teammates to complete the task; and they developed their displayed English language skill and multimodal skill when they produce the public signs for communication in the public space. Simultaneously, through task-based activities, students develop their collaborative skills. Although a 
sign displayed may consist of a few words only, the word choice should reveal deep meanings and attract passers-by, especially when they are enhanced with colorful images, and are illuminated after sunset. As described by Shohamy (2012), the real complexity of language in the public spaces is as complex as the relationship between linguistic landscape and society, people, politics, ideology, economics, policy, class and identities, multilingualism, and multimodalities. Also, Gorter and Cenoz (2015) clarify that rules, regulations, viewers, sign makers and even technology determine how the signage of a territory is. Basically, language in the public spaces is neither arbitrary nor random (BenRafael \& Shohamy, 2015).

As digital tools have become part of the students' life in the real world, in the present Linguistic Landscape Multiliteracy Task, students are supposed to use digital technology in creating their own linguistic landscape texts. The outcomes of the activity for each team are three public signs displayed on Sukarno-Hatta Boulevard in Malang City, Indonesia.

In the tasks students are supposed to reproduce mock monolingual English signs for the existing three outlets or offices, or to design three signs for their own mock new places of business on the boulevard. Since most of the existing signs use familiar simple words, students are supposed to use words or phrases with more sophisticated and complex meanings similar to those used in English speaking countries (Kweldju, 2018). The task is intended to push the students to develop their English skill for public display.

\section{THEORETICAL FRAMEWORKS}

The Youth-Oriented Sukarno-Hatta Boulevard: Geosemiotic Approach

Geosemiotics studies the city, especially how signs appear in the real world to create social literacy practices. Signs in the city depend on their context of diverse interactions of spatial, individual, social and cultural factors. In the present task, the geosemiotic framework utilized is only limited to the indexicality principle for designing the storefront signage of Sukarno-Hatta Boulevard, with the idea that the street is a dynamic, trendy, youthful, with free Wi-Fi hotspot access. For the instructional purpose of the present task, however, students were required to use English for the text and discourse of the mock signs they design, as how the language is creatively used in the public spaces in English-speaking countries. The task also deals only with one out of the three subsystems of geosemiotics, that is visual semiotics which focuses on the use of icons and signs (Scolon \& Scollon, 2003).

Students nowadays are familiar with modern visual signs around them in public places. Kressand Van Leeuwen (2006) refer to linguistic landscape as semiotic landscapes which encompass pictures in the form of texts, images, photographs, graphs, paintings and other combinations of these and others. As long as literacy in concerned, linguistic landscape texts are public texts that provide students with the opportunity to be exposed to the real use of language in context (Zabrodskaja\& Milani, 2014). One important context is the audience's attitudes.

The second driving factor behind this is the new emerging practice of the use of social media, especially Instagram where the users worldwide can easily share their photos and videos. Needless to say the entrepreneurs in the area decorate and design their outlets as trendy as possible for the purpose of photographicability and instagrammability for their young customers and clients. In fact, among the eight most dominant photo categories in Instagram, food and fashion are the favorable themes (Hu et al., 2014).

Sukarno-Hatta Boulevard is a street with a high density of signs, and mostly are in English, or trans-lingual, a combination of English and Indonesian. However, most of English words on the public signs are high frequency words familiar to and easy to pronounce by Indonesian people; some others are those which sound or spell like English, but they are not words in English. The presence of those English-sound texts is not used for informational purpose, as they lack information messages. They are without denotative, connotative or stylistic meaning, but used solely for symbolical purpose of foreignness for status raising and for the image of pop culture products, to attract young people to make themselves feel connected to the world.

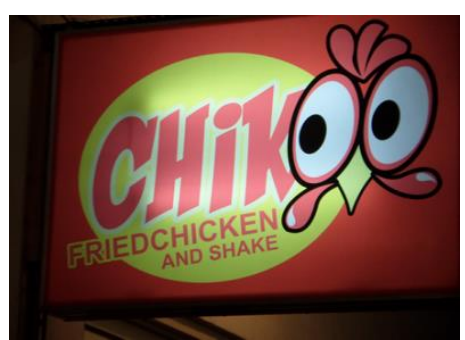

Chik, Fried Chicken and Shake are words/a phrase very familiar for Indonesian people.

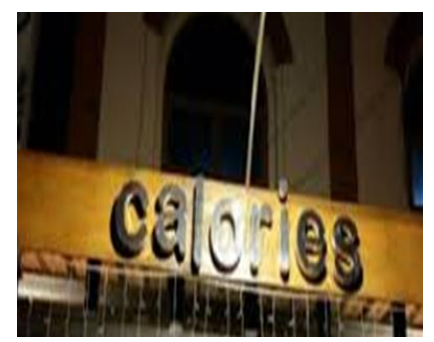

The word calories is familiar for Indonesian people. It is a loan word and spelled as: kalori 


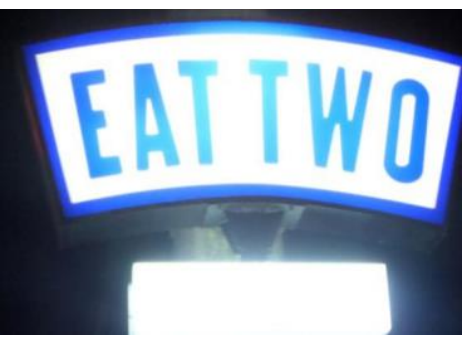

In English "eat for two" is meaningful but not "eat two"

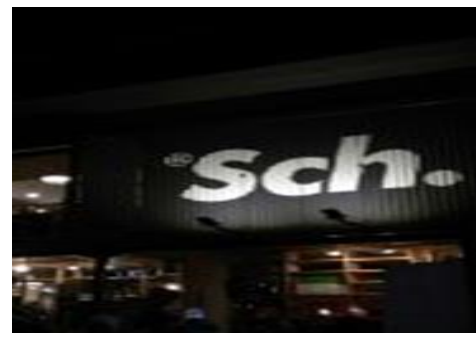

It is written using English spelling system but without any denotative or associative meaning.

\section{Figure 1: Examples of English names for restaurants on Sukarno-Hatta Boulevard}

In brief, generally, the multimodality of the linguistic landscape of Sukarno-Hatta is constructed as a magnet for young people. They are designed to meet the trendy, young people's lifestyle in internationally-connected world and the social-media networking. As a place the boulevard is young people's playground to build their networks and to entertain themselves, and as a space it marks the power of young people's and college students' participation in influencing shop owners and vendors to produce shop signs, notices, posters or billboards lining along the street to meet their aspirations, interests, and collective identity. Passers-by can easily notice the modern visual signs, especially during night time how the streets are lit by illuminated signs which mark the streets with the identities and lifestyle of modern young clients.

\section{The Theoretical Multimodality and Visual Grammar}

Multimodality focuses on both the verbal and visual aspect of texts. Therefore, multimodality does not only consider contents, but also the aesthetics of the overall design of a multimodal text which, at least, includes writing and images with their colors, fonts, shapes and the overall layout of the page. Aesthetic is not exclusively for a work of art, but also for the enjoyment of everyday experience (Dewey, 1980; p.11). Aestheticized experience on the street is synonymous to style, symbolism and fashion (Hancock, 2013).

As multimodality needs the interaction between verbal and visual components, the two should work together to create a coherent text message. Thus, building multiliteracy skills in students is to develop their ability in using and combining different semiotic modes in ways that are appropriate to a given context, or to a unique demand in a specific situation (Van Leeuwen, 2017).

The study of multimodality from the linguistic perspective was first introduced by Kress and van Leeuwen (2001), who emphasize that semiotic modes of communication comprise both language and visual meaning-making representation; each is informational and symbolic, and has its own division of semiotic labor. The language text is normally informative, appealing and stimulating. Aside from denotative meaning, it may also convey associative meaning, stylistic meaning, and socio-cultural meaning. In the same vein, Spolsky (2009) has also highlighted, the verbal text in advertisement, especially, should be informative, use the language desired by the readers, and also consider the use of languages with certain associations of symbolic conditions.

The visual componentis useful for what can be too long to read, and are very effective to encapsulate cultural and situational contexts. It includes graphics, layouts, sound, music, gestures, animation, and so forth. Particularly for linguistic landscape signs, the visual text comprise materiality, graphics, colour, font, layout, framing, image, angle, dimensionality, permanence, temporality, and emplacement. Another important aspect in multimodality of the aesthetic dimension of the uses of layout, colour and typography, and the modes of digital technology that suits the purposes of the multimodal texts (Scollon \& Scollon, 2003, p.vii; Constantinou, 2005).

Colours stimulate sensations and activities, and they are used to highlight specific aspects of the overall message. Equally, varied sizes and shapes of typeface and fonts are used to marshal the representational and communicational force of image and word. In this context, grammar is not only linguistic but also visual. Visual grammar is developed based on functional grammar or Hallidayan linguistics (Halliday, 1994) combined with semiotic principles for the theoretical study of image-text relation. According to Halliday (1978) visual texts can represent something about the world, their authors and addressees, and shape cohesion, information structure and different truth-values toward what is represented.

Visual communication has resources for representation, interaction and composition, which is analogous to the three metafunctions in Hallidayan systemic-functional grammar: ideational, interpersonal and textual (Chen, 2016).In terms of representation, image can narratively represent the 
world in terms of 'doing' and 'happening' (Kress \& Leeuwen, 2006); interaction refers to the "interaction between the producer and the viewer of the image" (Kress \& Leeuwen, 2006); composition consists of three aspects: information value, salience and framing. The information values include the values of Left and Right, Top and Bottom and Center and Margin; salience is highlights of the most outstanding elements in the page; and frames are used to connect or separate the different elements in the page, like joining the elements inside a visual composition and inside a written text (Kress \& Van Leeuwen, 2001, 2006).

It provides detailed and explicit methods for analyzing the meanings established by the syntactic relations between people, places and things depicted in images. These meanings are manifested in three ways: the physical or semiotic representation of entities, the interactive nature among viewers and what is viewed though the image constructs, and the composition or the distribution of information value or the relative emphasis among elements of the image (Roberts \& Philip, 2006).

In this project plan, the composition of multimodal text and the multimodal representation are the two concepts to introduce to students as the basis for understanding visual grammar. Concerning the composition of multimodal texts, there are three main aspects of information value to consider; that is, the three places in which the different elements of information appear: from left to right, from top to bottom, and from the center to the margins.

\section{METHODS \\ Subjects}

The subjects of the study were 68 students who were at their fifth semester of the English Language and Literature Program, Department of English, Universitas Negeri Malang. Most of them were 20 years old and turned tobe 21, and Bahasa Indonesia is their native language. English is a foreign language in Indonesia, and Indonesian people's English is the product of classroom learning.

\section{Linguistic Landscape for Developing Multimodal Analysis Skill}

Linguistic landscape task is used as a new learning environment to develop students' multimodal analysis skill, because linguistic landscape houses multimodal texts. Cenoz and Gorter (2008) also claim that linguistic landscape is useful for the acquisition of multimodal literacy skills.

The present task requires the students to produce their multi-literary text in the linguistic landscape of Sukarno-Hatta Boulevard. Sukarno-Hatta Boulevard is actually a street filled with delightful, trendy cafes, restaurants, clothing shops, bakeries, coffee carts, leisure facilities, for different tastes and budgets. It also has offices, computer shops, garages, and hospitals. On the 2-km-long boulevard, people can find universities and colleges. People have wide selection of cafes and food outlets, a playground for college students and young people who give trendy and youth-oriented flavor to the boulevard.

Language-wise, students need more examples of how word play, homophones, and other different forms of linguistic creatively is used in public texts. To develop the students' practical multimodal analysis skill, classroom language instruction needs to facilitate students' understanding of semiotic resources, modes of communication and intersemiotic relationship (Alvarez, 2016). The linguistic design and the visual design in public signs are used to introduce the two key modalities.

That linguistic landscape is efficient for teaching multimodality is because the urban environment today has a high density of linguistic landscape, developed with digital multimodality. It is a good choice to raise students' awareness of the need of literacy shifts that is taking place in the society. It also helps students to develop their multimodal competencies through what is accessible in real life. As a matter of fact, Scollon and Scollon (2003) already highlighted that signs and symbols are all around us, and their emplacement is the important factor for meaning-making.

\section{Designing the Multimodal Task-based Activities: Linguistic Landscape}

Task-based approach is used for the project, because the approach is the most suitable one for developing linguistic classroom activities with direct connection to real-life situation. The activities are meaningful and student-centered as the students creatively use English as language text, and images as visual text for producing their task outcome.

The activity can be divided into three stages: Before, during and after the process of the production of linguistic landscape. In order that students can carry out the tasks appropriately, guidelines are provided and explained to them for maximizing their production and achievement.

\section{Before the Linguistic Landscape Production Stage}

At this stage, the instructor explains to the students what linguistic landscape is, and what a multimodality text is. Linguistic landscape texts can be advertisements, government signs and graffiti. They can be delivered in various types of media such as billboards, window displays, street signs, warning signs, and announcements. Students are made familiar with the authentic English and the 
visual text they can find on the public signs in English speaking countries. Then, students are expected to produce their own three linguistic landscape items.

Before students produce their own linguistic landscape texts, they practice how to interpret visual texts, in order that they can smoothly articulate their visual meaning. An exercise is provided to develop their preliminary understanding of the multimodal texts. A class discussion is carried out to focus on the analysis of the modality of signs in the linguistic landscape of downtown Los Angeles, and try to understand them, verbally and visually, which is called by Kress and Van Leeuwen (2006) as visual grammar. Students need to understand that a linguistic landscape of an area has its own audience, and the multimodal text of the area needs to portray a particular social reality of the targeted audience. As most public signs are advertisement, students also need to be aware of the marketing strategies employed by the sign makers.

\section{Visual Grammar: Understanding Pictures}

To understand pictures, students are provided with a sign of which in the center is a young man, surrounded of people around him in smaller sizes. In its semiotic function the young man plays the role of an Actor. He is looking directly at the viewers as the interactive participants, instead of looking at the other represented participants in the image. The man's eye direction indicates that the young man wants the viewers' attention and then persuades the consumers to buy the products (Chen, 2016). The man's position in the center of the advertisement instead of the margin of the picture is to actively engage the viewers. Also, the students are made aware of how the visual design can take up a large or small part on the LL item.

\section{Understanding Multimodality Text}

First, to make students aware of image-text relations of a multimodal text, students are guided to analyze signs with the following characteristics (McCloud, 1994):

a. Word specific, where pictures illustrate but do not significantly add to a largely complete text;

b. Picture specific, where the picture dominates and words do not add significantly to the meaning of the image;

c. Duo specific, where words and pictures send essentially the same message;

d. Additive -words amplify or elaborate on an image or vice versa;

e. Parallel -words/image follow different courses without intersecting;

f. Montage -words are treated as integral parts of the picture;

g. Interdependent -image/words together convey an idea that neither could convey alone. It gives a generalized view of visual-verbal balance of meaning.

Second, students are provided with examples to make them aware of visual grammar:

a. Salience of a visual text: the elements which most attract their attention. For example, the bright color, the picture, etc.

b. Image representation: the actual happening in the image, the actions and the setting.

c. Realism: how realistic the image is, such as naturalistic or not (e.g. fairly saturated and modulated color).

d. Engaging: how the image can engage the viewers.

e. Coherence: how all the elements combine together to make a coherent visual text.

Thus, concerning modes, students pay attention to the English they use and the graphic resources such as font type, size, punctuation and colors. In images, students pay attention to the framed space, size, color, shape, icons of various kinds-lines, circles.

\section{During the Linguistic Landscape Production Stage}

The production stage is for students to complete a task in a group of four. One benefit of the activity is to enable students to do their English communication task for developing their English proficiency. The other benefit is to improve students' display English and multimodal skills. During the production stage, students work in a team of four to create their linguistic landscape display. The teacher facilitates and offers encouragement when necessary, and he may also highlights and expands important ideas that students produce.

The focus of the production stage is to produce the multimodal signs; students are actively engaged in a discussion to develop their multimodal plan. During the discussions, students concentrate on the message content, without consciously deal with language as form. They creatively and freely use English as a means of communication to develop their linguistic landscape, as they are given the freedom to develop their own multimodal linguistic landscape in multiple ways. They need to think aloud and to do research to find interesting names for their businesses; for example, in finding interesting wordplay, idioms, and words with catchy associative meaning in social and cultural contexts. They are 
also encouraged to use digital technology. Only when they are uncertain with technology can they manually develop their multimodal text.

As students are preparing a multimodal text, they are not writers anymore. Instead, they now turn to be designers, as they work on modes, media, frames, and sites of display, with rhetorical purposes, the designer's interests, and the characteristics of the audience, and how they focus on the dynamic interplay of language, visual elements and other semiotic means in public signage. Students may design top-down and bottom-up signs on a city street. They can be storefront signs, office-front signs, warning signs, billboards, posters etc. with white manila paper and colors as the medium.

Students begin the activity with discussing in their teams what they plan to design, carry out their plans, and report to the class what they will develop. They may receive questions and answer their peers' clarification questions, and receive suggestions, as well.

During the activity, students keep speaking English among themselves. They are also encouraged to use search engines to explore new information and new ideas for the English text and visual text. Through the activity students can develop target language fluency throughout the activities, and the outcome of the task can make them proud of their efforts and develop their confidence.

\section{After the Linguistic Landscape Production Stage}

Students present their linguistic landscape to class. Students and teachers give important comments and encourage feedback on what emerges from the task.

\section{Task-Based Linguistic Landscape Instruction}

Students work in a group of three and use multimedia tools to create three signs as shop-front signs for a street called Sukarno-Hatta in Malang. Students should make themselves familiar with the street, and explore Sukarno-Hatta Street to discover how it is dominated by shops and restaurants named in simple, familiar English. Students replace the familiar simple English names with names of deeper associative meaning as they are desirably used in English-speaking countries, like Rag and Bone for a clothing store, and Wok this Way for a Chinese restaurant chain. Students are encouraged to use wordplay.

Steps to perform the linguistic landscape multimodal task:

Step 1: Before coming to class, every student has explored the Sukarno-Hatta Boulevard. Students look for the signs that they want to multimodally replace with their own new designs.

Step 2: In class, students work together in teams of four. Discuss with teammates what and how new signs are developed. During the discussion every student has to actively contribute their ideas; s/he has to actively speak and listen. Then, come up with the multimodal designs of the signs. During the discussion, students exchange information and ideas. Only English is spoken.

Step 3: Following the discussion in their respective teams, each team has to find a partner team to work together with. Each team has to present its tentative decisions to its partner team for feedback. The partner team members have to actively listen and speak to provide feedback, in order that each of them can contribute to help their partner team to successfully reach the functional goal of the task.

Step 4: Discuss again with the teammates what they decide to do and how they can consider the other team's suggestion to their work.

Step 5: Undertake the production.

Step 6: Present the production to the class.

\section{FINDINGS}

Students' Multimodality Product, Appreciation and Feedback

At the end of the project, students were proud to display and to present their work as their own authentic problem-solving product for real-world goals. There were seventeen groups of students presenting their final multimodality products. In total fifty-one signs were produced. Most of the students tried to be as unique and interesting as possible in their store-naming activities and logo design, especially when students' work was expected to be particularly rich in wordplay. Meaningful appreciation was given to every team for their enthusiasm to design the storefront signs. Paying full attention to every design and genuinely giving compliments were helpful for enhancing students' next learning and building their self-esteem.

However, as compliments were not intended for flattery but for pedagogical purpose, in order that students could still improve their present work and their efforts in their next learning opportunities, effective feedback from the instructor and classmates were also provided for the students. They should also be aware that the only goal of the feedback was for students' next performance improvement and learning enhancement; therefore, the feedback should not discourage their efforts and leave them with the feeling of being defeated. 


\section{Stimulating Store Names and Visual Design}

Some storefront signs and the business names the students created were interesting, catchy, informative, appealing and stimulating. A team of students, for example, designed an interesting storefront signage with a stimulating store name Cap.able for a hat shop. This design matches very well with the environment of Sukarno-Hatta Boulevard.

To express the appreciation, the instructor highlighted that the design of Cap.able exemplifies a successful product that meets the requirements of information value, salience, image representation, coherence, engagement, and framing. It does not only pass the content, but also the aesthetics of the overall design of a multimodal text, with its well-selected colors, fonts, shapes and the overall layout.

To describe their design, the team wrote that black and white image evokes the feel of luxury, elegance, power and sophistication. That is to reflect that their goods were high-quality headwear.
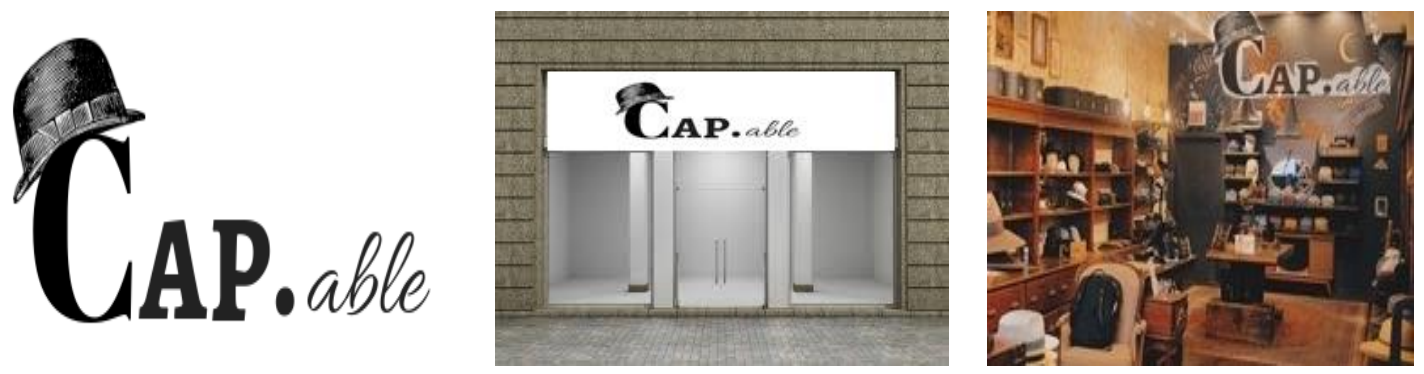

Designers: Migdad Z.M., Raynaldy Y., Rizka, A.K., Sarah, M.F.

Figure 2: Store front sign of Cap.able

To denote that the business specializes in different types of hats, a bowler hat is planted on top of the giant letter $\mathrm{C}$. It creates saliency for a catchy display that helps customers notice that the shop sells headwear. The position of the hat is on the topmost of the image, parallel with the position of a hat when it is worn on human head.

The bowler hat was selected by the team to symbolize the shop because of its historical reason, and the journey how bowler hat could be accepted by the upper classes in the United Kingdom, Ireland and the East Cost of the USA in the $19^{\text {th }}$ century. Bowler hats were known for their protectiveness and durability which suited the working classes very well-such as cow boys and railroad workers-- before they became a fashion for the upper classes. They were so strong that they could stand the strong wind. The strength of bowler hats was used to represent the high quality of the selections offered by Cap.able.

The insertion of dot between Cap and able is not only to make the syllable "cap" stand out, but it also represented the symbol of online-ness. All Cap.able items can be purchased online.

\section{The Use of Interesting Phonological Wordplay}

A team of students design a multimodal store front sign for a hair salon and named it "Dye Cut". We can find the word die cutting as an entry in a dictionary, but dye cutting is obviously the team's make-up compound word, deliberately created during the task. They playfully used the word "dye" in place of "die" which sounds the same but has different meaning and spelling. Die cutting is a process of cutting leather and other low-strength materials, or a process of cutting shapes from paper or plastic by pressing it with a sharp knife. Dye Cut is a good name for a hair salon as it fits to describe the hairstylists' duties that include hair coloring and haircutting.

Concerning the visual design, the use of black color as the background of the sign denotes prestige and elegance. The pink icons to pair with the black background makes the message harmoniously stand out. Using the silhouette icons of male and female head clarify that the hair salon is for both men and women; and the use of scissors and comb icon, brush and cosmetic tube icon reinforce further the activities in the salon, and make the salon more memorable. The text Dye Cut-The hair Factory is displayed in white makes the timeless contrast of black and white emphasize the show effect of classicism. 


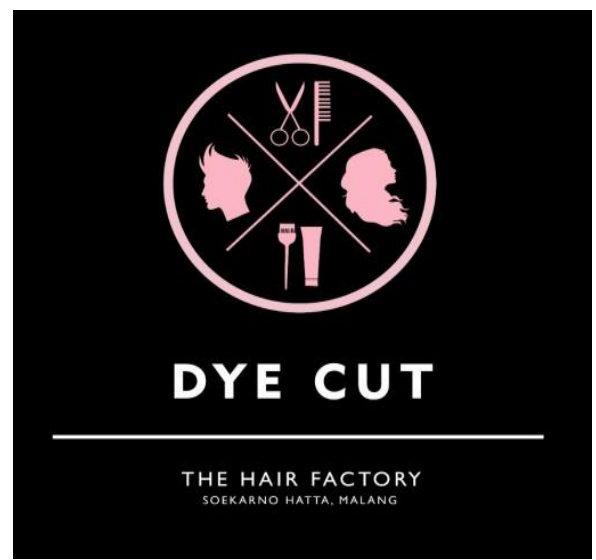

Designers: Nur Azizah, Rizka

Khurin N, Zulaikha Ira, Tiffany Elok

Figure 3: Store front sign of "Dye Cut"

Effective Feedback for Too Simple / Descriptive Name

During the final presentation it was discovered that a few signs students created were still linguistically too descriptive, and were not desirably unique and stylistic for a desirable display in English-speaking public spaces.

In the real world a businessman may name their business as simple and descriptive as possible to reflect what their business is; for example, if they sell gemstone, they may name their shop as straight forward as "Gemstone".

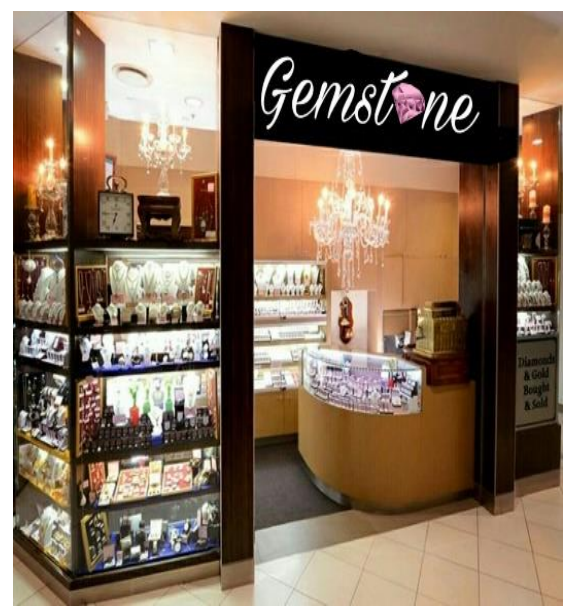

Figure 4: "Gemstone" Store

Likewise, a team of students in this task nicely designed the store front sign with a store name "Gemstone" printed on it. According to the proposed task, however, students are supposed to avoid a simple, descriptive name, such as Gemstone. Instead, they need to maximize their efforts in generating both the visual design and the display English to produce a new and amusing product.

To help students cultivate more efforts in generating more unique, stimulating, and memorable names, the instructor showed them the common names for gemstone stores in English speaking countries, and provided them with some possible creative names that might inspire them to create their own names:

(a) Gemstone business which involves craftsmen and jewelers has existed for at least 2,000 years. In the past people named their business after themselves, and some of those companies or shops are still running today, and they keep their traditional names. Therefore, to exemplify, some jewelry shops found in Toronto, Canada, are named Ashok Jeweller, Noor Jewellers for South Asian Jewellery, Bandiera Jewellers for Italian Jewellery, to mention some.

(b) The recently established gemstone shops in English-speaking countries, however, are very creative in generating names with more complex meanings such as Made You Look, The Devil's Workshop, Made for Her, Beadniks, The Velvet Box, and Pandora's Box.

Also, the teacher showed to the students that they could generate more creative names to replace the name Gemstone. The use of wordplay such as Gem Station, Stepping Stone can be more interesting. Even when they use one word only can be more unique, such as Gemstar, Gemlite, 
Gemware, Gemology, Glitter, Luxter, Brightzy, Jewelite, Hylite, and Twilite, Those words can evoke meaningfulness, easily pronounced and recalled, easily typed to Google, captivating, and may reflect the products to sell.

\section{Effective Feedback Names with Lack of Originality}

A team of students chose to design the storefront sign of an ice cream shop, and named it Frostbite. Frostbite means injury to body tissues caused by exposure to below-freezing temperatures. In this context, however, the compound word frostbite can also be used for an associative meaning by breaking it down into two free morphemes, frost and bite. The word frost describes ice cream as a frozen dessert undergoing a freezing process. The word bite is used to replace the word eat or lick.

However, the present task could not fully recommend this name. An ice-cream parlor, ice-cream shops or an ice cream bar called Frostbite are already found in many different cities and countries in the world. When students make a design, they are supposed to make sure the uniqueness and originality of their design.

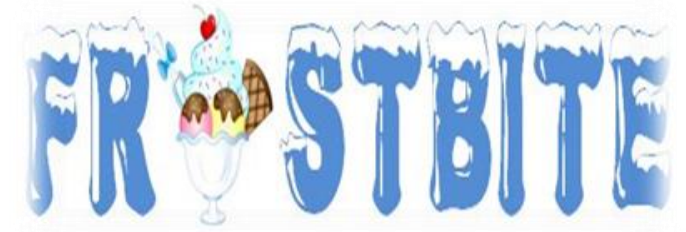

Figure 5: The storefront sign of an ice cream shop, Frostbite

Another example is when another team of students used the idiom "butter up" for the name of a bakery.

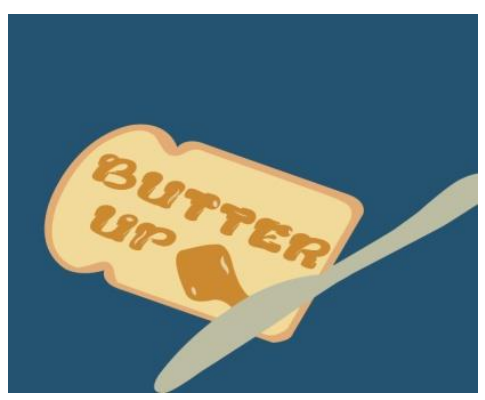

Figure 6: "Butter up" Logo

Butter up itself means to charm or to be nice to someone in the hope he will do a favor in return. However, when "butter up" is used for a bakery, it can be used as a pun by redefining "butter up". However, there have been too many bakeries called "Butter Up" in many different cities in the world. Students were expected to avoid using the name.

\section{Effective Feedback for Students Overlooking the Structures of Wordplay}

Wordplay is interesting for a catchy shop name. It helps people to remember the shop from the hundreds of others in the city by remembering the humor built in the name. Homophone is an important element of wordplay on sounds and meaning of words.

A team of students, for example, designed the storefront sign of a watch shop and called it "Wood n' Watch". In spite of the interesting name in itself, the students seemed to overlook the homophonic and homographic value of the word watch that suggests two meanings. It will be more interesting if students could maximize the homophone to produce a more memorable wordplay. For example, one alternative to suggest to the students is "Watch UR Watch".

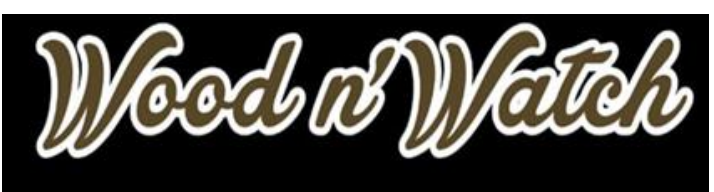

Designers: Adam Maheksya, Izza Indriyana, Nabilah Haruna, Tia Farahdiba

Figure 7: “Wood n' Watch” Logo 


\section{CONCLUSIONS AND SUGGESTIONS}

Literacy today should be multimodal because in the present digital era images have become more powerful than at any time before. Digital tools have also become part of the students' life in the real world. Linguistic landscape which is rich with multimodal representations is a good environmental context and tool for students to develop their multimodal literacy which focuses on both the verbal language and visual image of texts. In this project, linguistic landscape is understood from the geosemiotic perspective. Multimodality is not only for contents, but also the aesthetics of the overall design of a multimodal text.

A task-based digital multiliteracy project using linguistic landscape as a learning environment is developed. As all learning activities are intended to develop students' knowledge, skills and attitude, the aim of the instructional model is to promote the students' spoken and written English language skills, displayed English, visual communication skills, and collaborative skills.

Using digital technology students create their own linguistic landscape texts to display on the dynamic, trendy, youthful, free Wi-Fi-connected Boulevard called Sukarno-Hatta Boulevard in Malang City, Indonesia. The signage students developed replaces or improves the existing signs, most of which bearing shop names in simple English, familiar to and easy to pronounce by Indonesian people; some others are those which sound or spell like English, but they are not English.

Task-based approach is adopted to enable students develop their general English proficiency with the outcome of creating display English, and good visual communication skill, develop their collaborative skill, their research and information skill.

The activity can be divided into three stages: before, during and after the process of the production. Before the activity, equipped with a written guideline, the instructor helps students to construct the knowledge of multimodal text and multimodal representation as the basis for understanding visual grammar. Students are also exposed to plenty examples of how wordplay, homophones, and other different forms of linguistic creatively are used in public texts. During the activity, students keep speaking English among themselves, using search engines to explore new information and new ideas for the English text and visual text, planned the design, and reported to the class what they planned to develop, received questions and suggestions, and gave their responses. At the end of the activity students displayed and presented their work.

The Task-based Multimodal Linguistic Landscape Task has been introduced to sixty-eight (68) fifth semester students of the English Language and Literature Program of the English Department of State University of Malang. Working in fours, there were seventeen groups of students presenting their final multimodality products. In total fifty-one signs were produced. They were all excited about the task, because they found it like real-world learning experience and stimulating to their imagination. Also, it could help them experience a bit of real advertising world. Meaningful appreciation and feedback were given to every team for their enthusiasm, creativity, and the road to future learning.

\section{REFERENCES}

A \& Milani, T.M. (2014). Signs in context: multilingual and multimodal texts in semiotic space. International Journal of the Sociology ofLanguage, 228, pp.1-6.

Álvarez, J. (2016). Meaning Making and Communication in the Multimodal Age: Ideas for Language Teachers. The Colombian Applied Linguistics Journal,18(1), pp 98-115

Barton, D., Hamilton, M. (1998). Local Literacies: a Study of Reading and Writing in on Commuity. London : Routledge.

Ben-Rafael, E. \& Shohamy, E. (2015). Introduction: Linguistic Landscape, a New Journal. Linguistic Landscape 1(1/2), pp.1-3.

Cenoz, J., \& D. Gorter (2008). Linguistic Landscape as an additional source of input in second language acquisition. IRAL, 46, pp. 257-276.

Chen, S. 2016. Linguistic Landscape and Space: A Multimodal Analysis ofLinguistic landscape in Robot Open Space. International Journal of Applied Linguistics \& English Literature, 5(6), pp. 90-8.

Constantinou, O. (2005) Multimodal discourse analysis: Media, modes and technologies. Journalof Sociolinguistics, 9(4), pp. 602-618.

Cope, B., Kalantzis, M. (2000) Designs for Social Futures. In Cope, B. \&Kalantzis, M. (Eds) Multiliteracies: Literacy learning and the design of social futures. New York: Routledge.

Dewey, J. (1980). Art as Experience. New York: Perigee.

Ganapathy, M. \&Seetharam, S. (2016). The Effects of Using Multimodal Approaches in Meaning-Making of 21st Century Literacy Texts among ESL Students in a Private School in Malaysia. Advances in Language and Literary Studies, 7(2),pp. 143-155 .

Gee, J.P. (1996). Social Linguistics and Literacies: Ideology in Discourses. London: Taylor \& Francis. 
Gorter, D. \& Cenoz, J. (2015). Translanguaging and Linguistic Landscape. Linguistic Landscape, 1(1/2), pp.54-74.

Halliday, M.A.K. (1978). Language as Social Semiotic: The Social Interpretation of Language and Meaning. London: Arnold.

Halliday, M.A.K. (1994). An introduction to functional grammar (2nd ed.). London: Edward Arnold.

Hancock, P. 2003. Aestheticizing the World of Organization - Creating Beautiful Untrue Things. In A. Carr and P. Hancock (eds.), Arts and Aesthetic at work, New York: Palgrave, Macmillan, pp.17495.

Hu, Y., Manikonda, L., and Kambhampati, S. 2014. What We Instagram: A First Analysis of Instagram Photo Content and User Types. Proceedings of the Eighth International AAAl Conference on Weblogs and Social Media, pp. 595-8.

Kress, G., \& Van Leeuwen, T. (2006). Reading Images: The Grammar of Visual Design (2nd ed.). London: Routledge.

Kweldju, S. 2018. Autonomously riding google maps to travel to English speaking countries: linguistic landscape. Journal of English Language, Literature, and Teaching, 2(1), pp. 5-13.

Lirola, M.M. \&Castejón, L.I. (2014). Introducing culture and critical thinking in the classroom: Analysing multimodal texts from NGOs in a Masters course. Argentinian Journal of Applied Linguistics, 2(2), pp.5-22.

McCloud, S. (1994). Understanding comics: [the invisible art]. New York: HarperPerennial.

Roberts, S. \& Philip, R. (2006). The grammar of visual design. Australasian Journal of Educational Technology, 22(2), pp. 209-228.

Scollon, R., and S. Scollon.2003.Discourses in Place: Language in the Material World.London:Routledge. Shohamy, E. (2012). Linguistic Landscape and Multilingualism. In MarilynMartin-Jones (ed.), The Routledge Handbook of Multilingualism, New York, Routledge, pp. 538-51.

Spolsky, B. (2009). Prolegomena to a Sociolinguistic Theory of Public Signage. In E.Shohamy and D. Gorter (eds), Linguistic Landscape: Expanding the Scenery. New York: Routledge, pp. 25-39.

Van Leeuwen, T. (2017). Multimodal Literacy. Viden om Literacy, 21, pp. 4-11.

Zabrodskaja, A \& Milani, T.M. 2014. Signs in context: multilingual and multimodal texts in semiotic space. International Journal of the Sociology of Language, 228, pp.1-6. 